Copyright (C) 2021 by Cherkas Global University

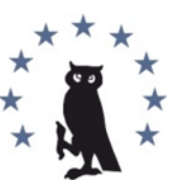

Published in the USA

European Journal of Physical Education and Sport

Has been issued since 2013 .

E-ISSN: 2409-1952

2021. 9(1): 13-24

DOI: 10.13187/ejpe.2021.1.13

https://ejpes.cherkasgu.press

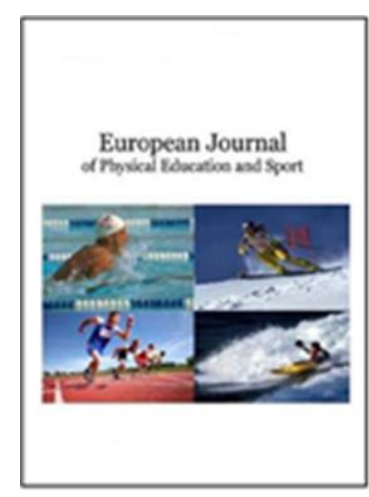

\title{
Knowledge, Attitudes and Practices Related to Doping among Cameroonian University-Level Athletes: A Cross-Sectional Study
}

Wiliam Richard Guessogo a , b * , André Hamadou a, Josué Bissou-Mahop a , William Mban-Bian a , b, Evariste Edmondo Djomo-Ngnoko a, Ruth Gaël Magne-Talla a, Abdou Temfemo ${ }^{\text {b }}$

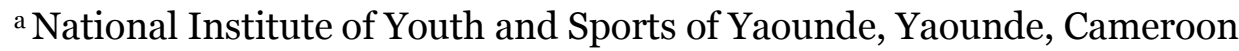

b University of Douala, Douala, Cameroon

\begin{abstract}
The need to maintain or improve physical performance often prompts athletes to resort to doping. The objective of this work is to assess the knowledge, attitudes and practices in doping of Cameroonian university-level athletes. One hundred and thirty-eight university-level athletes (100 male and 38 female) answered a self-administered questionnaire, providing information on their knowledge, attitudes and practices towards doping. The results show that $96.4 \%$ of athletes have knowledge about doping, 88.4 \% know about doping substances, $96.3 \%$ have a positive attitude towards doping and $90.6 \%$ have never used doping products. In addition, it had already been proposed to use doping products at only $33.3 \%$ and these proposals came from teammates (27.1\%), friends (24.6\%) and the coach (12.9\%). Regression analysis reveals that the risk of doping is 27 times $(\mathrm{OR}=27.10 ; \mathrm{p}=.00027)$ higher among respondents over the age of 30 . This risk is 5 times $(\mathrm{OR}=5.10 ; \mathrm{p}=.0486)$ higher in athletes who have had proposals for doping substances, and 25 times $(\mathrm{OR}=25.15 ; \mathrm{p}=.0170$ ) higher among respondents who indicated their intention to dope. Cameroonian university-level athletes have high knowledge about doping, however, a positive attitude towards doping and the practice of doping remains low. There is a need to improve doping education in order to increase knowledge on doping issue, and to establish appropriate doping control structures and policies.
\end{abstract}

Keywords: doping knowledge, doping attitude, doping practice, university athlete, Cameroon.

\section{Introduction}

Nowadays, the practice of high level sport requires a lot of preparation because of the frequency of the competitions, their intensity and the high financial stakes. This situation predisposes athletes to many traumas due to stress or homeostatic disturbances induced by the regularity of training sessions and competitions (Kreher, Schwartz, 2012). Therefore, recovery phases of satisfactory duration and quality are necessary in order to maintain an optimal balance and a good level of sports performance. A lacking of good recovery will lead to overload, thus can train the athlete to a state of fatigue or overwork, which will in turn lead to a decrease of performance. Due to the pressures that athletes face, exerted by their employer, supporters and close social circle, the need to maintain or improve their physical performance is increasingly felt

\footnotetext{
* Corresponding author

E-mail addresses: guessowiliam@yahoo.fr (W.R. Guessogo)
} 
(Boit et al., 2015; Government of Kenya, 2014). To do this, some athletes sometimes look for more or less illegal strategies, such as doping.

The aim of doping is to improve the functional and mental capacities of the individual through the use of prohibited substances and methods in order to maintain or increase the level of physical performance and consequently the chances of victory (International Olympic Committee [IOC], 1998; World Antidoping Code, 2009).

Doping is a serious health-threatening behavior with numerous negative consequences for athletes' health status (Honour, 2016; Mazanov et al., 2012; Kondric et al., 2011; Ljungqvist, 2014), that can lead to several deaths in athletes (Hausmann et al., 1998). According to the World Antidoping Agency [WADA] (2013), the number of sample abnormal analysis results recorded by anti-doping authorities around the world has increased by more than $20 \%$ since 2012. This percentage could be higher if systematic doping control were carried out with athletes, especially at the African level. However, the costs of carrying out these doping controls are high, especially for national anti-doping organizations like those of the majority of African countries.

Thus, from a research perspective, the studies have focused on evaluating the knowledge, attitudes and practices of doping among athletes, with the aim of establishing policies aimed at reducing the possibilities or doping intentions among the athletes concerned. Indeed, it is a question of warning athletes of the dangers to which they are exposed, in the short, medium and long term, because of the use of doping substances or methods. These studies have been carried out at the global, African and national levels.

At the global level, studies first focused on the validation of tools likely to assess the knowledge, attitudes and practices of athletes with regard to doping (Petroczi, Aidman, 2009; Brand et al., 2014 ; Malek et al., 2014; Rintaugu, Mwangui, 2021). Then, evaluation studies of these variables were carried out in various countries (Morente-Sanchez et al., 2019; Campian et al., 2018; Domagala-Rodacka et al., 2018; Al Ghobain et al., 2016; Sekulic et al., 2016). In addition, research aimed on the one hand at determining the prevalence of doping in sports (Al Ghobain et al., 2016; Sekulic et al., 2016), and at identifying predictive factors of doping on the other hand (Devcic et al., 2018; Bae et al., 2017; Blank et al., 2016a; Blank et al., 2016b; Sekulic et al., 2016) were performed.

At the African level, we record very little research in the field. However, a study carried out in Uganda established the attitudes, knowledge and practices of doping in a sample of Ugandan professional athletes in 4 contact sports (basketball, football, handball, rugby) and in 2 individual sports (athletics, cycling) (Muwongue et al., 2015). Similarly in Kenya, studies whose objectives were to assess the knowledge, attitudes and practice of doping among elite middle and long distance runners (Chebet, 2014) and to examine the knowledge, attitudes and and perceptions on doping among university students attending sports-related courses (Rintaugu, Mwangui, 2021) were realized.

In Cameroon, few studies also exist, only, we can quote those by Ama et al. (2003) who insvetigated the use and awareness of lawful and unlawful substances by amateur footballers in Yaounde and, Ama et al. (2002) who examined attitudes and knowledge about doping among pharmacists in the city of Yaounde in Cameroon.

As doping in sports is a problem that affects both elite and university athletes (Chebet, 2014), to our knowledge, there is no study carried out in Cameroon on this target, however universitylevel athletes constitute a breeding group in which elite sport draws its new talents. The objective of this research is to assess the knowledge, attitudes and practices related to doping of Cameroonian university-level athletes.

\section{Methods}

\section{Researh design and study participants}

A descriptive cross-sectional research design was used to identify the doping knowledge, practices, and attitudes of Camroonian university-level athletes, during the period of May to June 2020, in the University of Yaounde I, Cameroon. The study was approved by the Deputy Director of the National Institute of Youth and Sports of Yaounde, Cameroon. A total of 138 university athletes (27.5\% female and $72.5 \%$ male) regularly attending the national championship in their respective sports disciplines were enrolled in the study. The selection criteria targeted students who were athletes over 18 years of age and currently competing at the national level. Participants who did not competed in the past year were excluded. According to the sport discipline, since the number of 
athletes was high in football (47 athletes, 29.1\%) and handball (33 athletes, 20.5\%), we encompassed all the other athletes in one group. Regarding the age item, participants were divided into 4 categories $(<21 \mathrm{yrs}$; [ $21-25$ [; [25 - 30[; and, $>30 \mathrm{yrs})$. The average age of the sample was $26 \pm 4$ yrs. The sample size was calculated using Raosoft calculator with $95 \%$ confidence level, a maximum error of $5 \%$ and with a response distribution of $50 \%$ (recommended). All the participants gave their informed consent to participate in this study. Table 1 shows the participants' characteristics.

Table 1. Sociodémographic characteristics

\begin{tabular}{ccc}
\hline $\begin{array}{c}\text { Gender }(\mathbf{N}= \\
\text { 138) }\end{array}$ & & \\
\hline Female & 38 & $27.5 \%$ \\
Male & 100 & $72.5 \%$ \\
Mean age & $26 \pm 4$ \\
(years) & & \\
$<$ 21 & 19 & $13.8 \%$ \\
[21 - 25[ & 30 & $21.7 \%$ \\
[25 - 30[ & 57 & $41.3 \%$ \\
$>$ 30 & 32 & $23.2 \%$ \\
Sport discipline & & \\
Football & 47 & $29.1 \%$ \\
Handball & 33 & $20.5 \%$ \\
Others & 58 & $50.4 \%$ \\
\hline
\end{tabular}

\section{Instrument and data-collection procedure}

After a literature review, a questionnaire was self-constructed by the authors. The questionnaire intended to investigate the participants' knowledge, attitude and practice towards doping of Cameroonian university athletes. The questionnaire was reviewed and validated by an expert panel with the participation of university professors and the members of the Cameroonian Andi-doping Organization not involved in the project. It was then pilot tested to ensure and determine clarity and the panel of expert approved the final version of the questionnaire. This questionnaire was made of 4 sections. Section one sought the demographic details of the respondents (age, gender, sports participation). Section two of the questionnaire concerned knowledge of the respondents on doping. Section three sought information on attitudes of the respondents towards doping. This part of the questionnaire was adapted from the Performance Enhancement Attitude Scale (PEAS). Acceptable reliability indices of the scale have been reported in previous studies involving college and elite athletes (Moran et al., 2008; Petroczi, Aidman, 2009). Section 4 refered to doping practice and collected informations such as doping use and submission to anti-doping control. The data were collected by administering the questionnaire on different days from May to June 2020, at the training grounds of each discipline before or after training sessions. Instructions on how to complete the questionnaire properly were given before it was handed out. Athletes were informed that the data they provided would be used for academic purposes. Filling out the questionnaire was totally voluntary. Athletes were guaranteed complete anonymity, and written informed consent was obtained from each athlete before participating in the study.

\section{Data analysis}

Demographic variables were reported using descriptive statistics. Continuous variable were reported in terms of means and standard deviations and categorical variables were reported in terms of frequency distributions. As questions were single or multiple choice options, the proportions do not add up to $100 \%$ for the questions with multiple responses. Multivariate logistic regression was used to identify factors associated with the doping behavior. The outcome 
variable was the use of doping and the independent variables (factors) included gender, age, participation in competition, heard about sport doping, proposal of doping substances, knowledge of doping substances, submission to anti-doping control, intention to dope in the future, and sports discipline practiced. Odd ratios (brut and adjusted) along with their confidence interval at $95 \%$ (95\% CI) and level of significance were computed. A log-transformed value of likelihood was used to appraise the goodness-of-fit of each logistic regression model. All analysis were performed using IBM(C) SPSSC Statistics version 20 (IBM(C) Corp., Armonk, NY, USA). A p-value of < 0.05 was considered statistically significant.

\section{Results}

Table 1 shows the socio-demographic characteristics of participants. Almost $3 / 4$ of the participants $(72.5 \%)$ are male. Thirteen point two percent of them are less than 21 years old, $63.0 \%$ are between 21 and 30 years old, and $23.2 \%$ are over 30 years old. The most represented sport discipline is football (29.1\%), then handball (20.5\%).

Among the participants, 50.0 \% of them were elite athletes (Table 2). Of them, $24.7 \%$ belonged to the international level, $33.3 \%$ to the national level, and $7.2 \%$ to the regional level. Furthermore, $74.6 \%$ participate to competition and the majority trained for more than 1 hours per session.

Table 2. Sport participation

\begin{tabular}{lcc}
\hline Variables & $\mathbf{N}$ & $\mathbf{\%}$ \\
\hline Elite athlete $^{\mathbf{a}}$ & & \\
No & 69 & 50.0 \\
Yes & 69 & 50.0 \\
Which one ? & & \\
$\quad$ International & 17 & 24.7 \\
National & 23 & 33.3 \\
Regional & 5 & 7.2 \\
Not declared & 24 & 34.8 \\
Participation to competition & & \\
No & & \\
Yes & 35 & 25.4 \\
Duration of sport training session \\
(hours)
\end{tabular}

a Are you member of the sport elite?

${ }^{\mathrm{b}}$ Do you take part in the championship?

With respect to the general knowledge about doping (Table 3), $96.4 \%$ of the respondents declared that they have already heard of doping and $88.4 \%$ know about doping substances. The main source of information is the media (37.5 \%), followed by friends (24.6\%), colleagues 
(17.9\%), studies (9.8\%), coach (8.0 \%), and the parents (1.8\%). But, $72.7 \%$ of them can not cite doping substances. In the $27.3 \%$ remaining, the frequent substances cited were cocaine (9.1\%), guronsan (7.6 \%), anabolic steroids (6.1\%), Indian hemp (4.5\%), energy drinks (3.8 \%), and diuretics $(0.8 \%)$.

Table 3. General knowledge about doping

\begin{tabular}{|c|c|c|}
\hline Variables & $\mathbf{N}$ & $\%$ \\
\hline \multicolumn{3}{|c|}{ Received information $^{a}$} \\
\hline No & 5 & 3.6 \\
\hline Yes & 133 & 96.4 \\
\hline \multicolumn{3}{|c|}{ Source of information } \\
\hline Media & 61 & 37.5 \\
\hline Friends & 40 & 24.6 \\
\hline Colleagues & 29 & 17.9 \\
\hline Coach & 13 & 8.0 \\
\hline Parents & 3 & 1.8 \\
\hline Studies & 16 & 9.8 \\
\hline \multicolumn{3}{|c|}{$\begin{array}{l}\text { Do you know about doping } \\
\text { substances? }\end{array}$} \\
\hline No & 16 & 11.6 \\
\hline Yes & 122 & 88.4 \\
\hline \multicolumn{3}{|l|}{ Known substances ${ }^{b}$} \\
\hline Anabolic steroids & 8 & 6.1 \\
\hline Guronsan & 10 & 7.6 \\
\hline Cocaine & 12 & 9.1 \\
\hline Energy drinks & 5 & 3.8 \\
\hline Diuretics & 1 & 0.8 \\
\hline Indian hemp & 6 & 4.5 \\
\hline Don't know & 96 & 72.7 \\
\hline
\end{tabular}

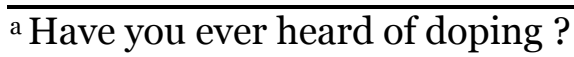

b Cite some substances you know

Concerning doping attitudes (Table 4), the main reason for doping declared is to improve performance $(76.8 \%)$. For $2.9 \%$ of the participants, doping increases agressivity and selfconfidence/courage for $10.9 \%$. When asked whether they think it is likely or unlikely that over the next year they will use doping products to improve their athletic performance, participants replied extremely unlikely (22.5\%), very unlikely (10.9\%), quite unlikely (27.5\%), very probable (4.4 \%), while $34.8 \%$ have no idea. Ninety six point three percent of the participants do not plan to dope, even if more than $3 / 4$ of them (72.8 \%) will not feel bad if they were using doping substances. On a scale ranging from o to $100 \%, 72.7 \%$ of the Cameroonian university athletes admitted that there is no chance for them to use doping substances to improve athletic performance. From 1 to $50 \%$ of chance, there are $23.5 \%$ of the participants who can use doping substances and, from 51 to $100 \%$, there is only $3.8 \%$. 
Table 4. Doping attitude

\begin{tabular}{|c|c|c|}
\hline Variables & $\mathbf{N}$ & $\%$ \\
\hline \multicolumn{3}{|l|}{ Doping reasons } \\
\hline Improve performnace & 106 & 76.8 \\
\hline Increase agressivity & 4 & 2.9 \\
\hline To have self-confidence/courage & 15 & 10.9 \\
\hline Don't know & 23 & 16.7 \\
\hline \multicolumn{3}{|l|}{ Probability to use doping products a } \\
\hline Extremely unlikely & 31 & 22.5 \\
\hline Very unlikely & 15 & 10.9 \\
\hline Quite unlikely & 38 & $27 \cdot 5$ \\
\hline Very probable & 6 & 4.4 \\
\hline No idea & 48 & 34.8 \\
\hline \multicolumn{3}{|l|}{ Do you plan to dope? } \\
\hline No & 132 & 96.3 \\
\hline Yes & 6 & 3.7 \\
\hline \multicolumn{3}{|c|}{$\begin{array}{l}\text { Would you feel bad if you were using doping } \\
\text { substances? }\end{array}$} \\
\hline No & 118 & 72.8 \\
\hline Yes & 44 & 27.2 \\
\hline \multicolumn{3}{|l|}{ Chances to use doping substances $b$} \\
\hline $\mathbf{0} \%$ & 118 & 72.7 \\
\hline 1-10\% & 19 & 11.7 \\
\hline $11-20 \%$ & 4 & 2.5 \\
\hline 21-30 \% & 7 & 4.3 \\
\hline $31-40 \%$ & 4 & 2.5 \\
\hline $41-50 \%$ & 4 & 2.5 \\
\hline $51-60 \%$ & 3 & 1.9 \\
\hline $61-70 \%$ & 3 & 1.9 \\
\hline $71-80 \%$ & o & 0 \\
\hline $81-90 \%$ & o & 0 \\
\hline 91-100\% & o & $\mathrm{O}$ \\
\hline
\end{tabular}

a Do you think it is likely or unlikely that over the next year they will use doping products to improve your athletic performance?

${ }^{\mathrm{b}}$ In the next year, what are the chances in 100 that you will use doping products to improve your athletic performance?

Regarding doping practice (Table 5), $90.6 \%$ of the participants declared that they have not yet been offered doping substances/methods, and for $66.7 \%$ of them, anyone never advised them to use doping substances. For the $33.3 \%$ remaining, advises reported to have come from coach (12.9\%), friends (24.6\%), colleagues (27.1\%), parents $(3.7 \%)$, and someone in the sport center (14.8\%). More than $3 / 4$ of the participants $(75.4 \%$ ) have never undergone doping control. 
Table 5. Doping practice

\begin{tabular}{lcc}
\hline Variables & N & \% \\
\hline Have you been offered doping substances/methods? & & \\
No & 125 & $\mathbf{9 0 . 6}$ \\
Yes & 13 & $\mathbf{9 . 4}$ \\
Has anyone ever advised you to use doping & & \\
$\begin{array}{l}\text { substances? } \\
\text { No }\end{array}$ & & \\
Yes & 92 & $\mathbf{6 6 . 7}$ \\
& 46 & $\mathbf{3 3 . 3}$
\end{tabular}

\section{Source of advise}

Coach

Friends

Colleagues

Parents

Someone in your sports center

Nobody
$21 \quad 12.9$

$40 \quad \mathbf{2 4 . 6}$

$44 \quad \mathbf{2 7 . 1}$

$\begin{array}{ll}6 & 3 \cdot 7\end{array}$

$24 \quad 14.8$

$27 \quad \mathbf{1 6 . 6}$

Have you ever undergone an anti-doping control?

No

Yes
$104 \quad 75.4$

$33 \mathbf{2 4 . 6}$

The associate factors with doping use are reported in Table 6. The results revealed that the risk of doping is 27 times $(\mathrm{OR}=27.10 ; \mathrm{p}=0.00027)$ higher in respondents aged over 30 compared to those under 21. This risk is 5 times $(\mathrm{OR}=5.10 ; \mathrm{p}=0.0486)$ higher in athletes who have had proposals for doping substances compared to those who have not had proposals, and 25 times $(\mathrm{OR}=25.15 ; \mathrm{p}=0.0170)$ higher among respondents who indicated their intention to dope compared to those who did not intend to dope.

Table 6. Risk factors with doping use

\begin{tabular}{|c|c|c|c|c|c|c|c|}
\hline Factors & & $\mathbf{N}$ & $\mathbf{N}(\%)$ & $\begin{array}{l}\text { OR }^{\mathrm{a}}(95 \% \\
\text { IC) }\end{array}$ & $\begin{array}{c}\text { p- } \\
\text { value }\end{array}$ & $\mathrm{OR}^{\mathrm{b}}(95 \% \mathrm{IC})$ & p-value \\
\hline \multirow[t]{2}{*}{ Gender } & Female & 38 & $2(5.3 \%)$ & 1 & & 1 & \\
\hline & $\begin{array}{l}\text { Male } \\
<21\end{array}$ & $\begin{array}{c}100 \\
19\end{array}$ & $10(10.0 \%)$ & $\begin{array}{l}2.00(.42- \\
9.58) \\
1\end{array}$ & .3858 & $1.23(.17-8.67)$ & 0.8354 \\
\hline
\end{tabular}




\begin{tabular}{|c|c|c|c|c|c|c|c|}
\hline \multirow[t]{2}{*}{ Age (years) } & {$[21-25[$} & 30 & $4(13.3 \%)$ & $\begin{array}{l}2.77(.29- \\
26.87)\end{array}$ & .1483 & $\begin{array}{l}68.94(.22- \\
21464.31)\end{array}$ & 0.1483 \\
\hline & {$[25-30[$} & $\mathbf{5 7}$ & $5(8.8 \%)$ & $\begin{array}{l}1.73(.19- \\
15.83) \\
-1.01-\end{array}$ & .1679 & $\begin{array}{l}52.28(.19- \\
14488.85)\end{array}$ & 0.1679 \\
\hline \multirow{3}{*}{$\begin{array}{l}\text { Participation in } \\
\text { competition }\end{array}$} & $>30$ & 32 & $2(6.3 \%)$ & 14.20) & .0088 & 9839.82) & 0.0027 \\
\hline & No & 40 & $2(5.0 \%)$ & $\begin{array}{l}1 \\
2.16(.45-\end{array}$ & & 1 & \\
\hline & Yes & 98 & $10(10.2 \%)$ & 10.33) & .3351 & $2.00(.28-14.27)$ & 0.4874 \\
\hline $\begin{array}{l}\text { Heard about sports } \\
\text { doping }\end{array}$ & No & 5 & $1(20.0 \%)$ & $\begin{array}{l}1 \\
0.36(.04-\end{array}$ & & $\begin{array}{l}1 \\
0.22(1.08 \mathrm{E}-3-\end{array}$ & \\
\hline \multirow{2}{*}{$\begin{array}{l}\text { Proposal of doping } \\
\text { substances }\end{array}$} & Yes & 133 & $11(8.3 \%)$ & $3.52)$ & .3799 & 43.43） & 0.5716 \\
\hline & No & 94 & $\begin{array}{l}3(3.2 \%) \\
9(20.5 \%)\end{array}$ & $\begin{array}{l}1 \\
7.80(1.99- \\
\text { 30.50) }\end{array}$ & .0032 & $\begin{array}{l}1 \\
5.10(1.01- \\
25.78)\end{array}$ & 0.0486 \\
\hline \multirow[t]{2}{*}{$\begin{array}{l}\text { Knowledge of doping } \\
\text { substances }\end{array}$} & No & 30 & $2(6.7 \%)$ & $\begin{array}{l}1 \\
1.43(.30-\end{array}$ & & 1 & \\
\hline & Yes & 108 & $10(9.3 \%)$ & $6.90)$ & .6572 & $1.41(.16-12.24)$ & 0.7565 \\
\hline \multirow{2}{*}{$\begin{array}{l}\text { Submission to anti- } \\
\text { doping control }\end{array}$} & No & 104 & $7(6.7 \%)$ & $\begin{array}{l}1 \\
2.47(.72-\end{array}$ & & 1 & \\
\hline & Yes & 34 & $5(15.2 \%)$ & $8.40)$ & .1463 & $2.94(.49-17.85)$ & 0.2403 \\
\hline \multirow{2}{*}{$\begin{array}{l}\text { Do you plan to dope in } \\
\text { the future? }\end{array}$} & No & 132 & $\begin{array}{c}9(6.8 \%) \\
3(50.0 \%)\end{array}$ & $\begin{array}{l}1 \\
13.67(2.40- \\
77.69)\end{array}$ & .0032 & $\begin{array}{l}1 \\
25.15(1.78- \\
355 \cdot 38)\end{array}$ & 0.0170 \\
\hline & Others & 58 & $3(5.2 \%)$ & $\begin{array}{l}1 \\
1.18(.19-\end{array}$ & & 1 & \\
\hline Sport discipline & $\begin{array}{l}\text { Handball } \\
\text { Football }\end{array}$ & 33 & $\begin{array}{c}2(6.1 \%) \\
7(14.9 \%)\end{array}$ & $\begin{array}{l}7.47) \\
3.21(.78- \\
13.18)\end{array}$ & $\begin{array}{l}.1058 \\
.8583\end{array}$ & $\begin{array}{l}0.71(.06-7.74) \\
5.55(.80-38.31)\end{array}$ & 0.7759 \\
\hline
\end{tabular}

$\mathrm{OR}=$ Odds ratio $; \mathrm{IC}=$ Confidence interval

$\mathrm{a}=$ brut $\mathrm{OR} ; \mathrm{b}=$ ajusted OR

\section{Discussion}

The present study was carried out to assess the knowledge, attitudes and practices of Cameroonian university-level athletes towards doping. At the end of it, we noted that university level athletes have a high knowledge of doping, they do not intend to dope in the future and almost $3 / 4$ claim that they would not feel not bad if they used doping substances. However, the use of doping substances and methods in academia by athletes remains low. In addition, age, proposals for doping and the intention to dope are the risk factors for doping among university athletes.

Regarding knowledge about doping, the present study revealed that $96.4 \%$ of the athletes surveyed had information about substances and substances and methods banned in sport. This high percentage could be justified by the fact that the people surveyed are university-level sportsmen and therefore have a level of understanding allowing them to better understand the effects of doping. These results suggest that an individual's state of knowledge about doping is influenced by their level of education (Muwongue et al., 2015). The results obtained in the present study reveal a higher percentage than those obtained in other previous studies which reported $93 \%$ among professional Cameroonian athletes (Ama et al., 2003), and $84 \%$ among elite Ugandan athletes (Muwongue et al., 2015). They are also higher than those of Erdman et al. (2007) who obtained a percentage of $76.7 \%$ among Canadian athletes, and than those obtained by Waddington et al. (2010) among members of the English Professional Football Association. Other studies reported a much lower percentage than our study. This is the case with Chebet (2014) among Kenyan elite athletes (46.4\%), and Albrecht et al. (1992) in elite athletes in the United States (36\%).

During this work, more than $76.8 \%$ of university sportsmen attribute the use of prohibited substances to improving performance, building self-confidence/courage (10.9\%) and increasing aggressivity (2.9\%). This reinforces the idea that resorting to doping increases and improves the performance of the athlete (WADA, 2009; 2015). These observations could have implications for 
the implementation of a doping awareness program, through which academic institutions could serve as channels for disseminating anti-doping messages (Morente-Sanchez, Zabala, 2013).

The majority of athletes in this study revealed that the main sources of information on doping were colleagues $(17.9 \%)$, friends $(24.6 \%)$, coaches $(8.0 \%)$ and especially the media $(37.5 \%)$. This result is in agreement with that of Erdman et al. (2007), who noted that family, friends and teammates were the most common sources of information on the use of doping products and substances in a group of 582 high performance Canadian athletes. This observation is contrary to that of Somervile and Lewis (2012), who indicated that the team doctor was the most popular source of information on doping substances and methods in a survey on 196 British Olympic-level athletes. The present study found that teachers are another source of information about doping. Indeed, some participants in our study are students who have anti-doping items in their training program. Therefore, anti-doping programs designed to target this group of people could have a significant impact on the doping knowledge, attitudes and practices of athletes.

Although most of the athletes in the present study indicated a modest knowledge of antidoping information, $83.7 \%$ of them could correctly identify why to dope as stated by WADA (2015). This finding could be a limitation of existing anti-doping programs, which can be corrected by appropriate educational programs (Morente-Sanchez et al., 2019). In addition, it should be mentioned that insufficient media coverage of doping-related themes and lack of awareness about doping is a serious concern in Cameroonian sport and may explain the lack of knowledge on some aspects of doping observed among athletes in this study.

With regard to attitudes about doping in sport, since attitudes could be considered as predictors of doping behavior, we examined in this study factors associated with a risk of doping use. Our results revealed that the risk of doping is 27 times (OR $=27.10 ; p=0.00027)$ higher in respondents aged over 30 compared to those under 21 years. These results are similar to a study in Kenya among elite athletes which indicated that athletes over the age of 30 said they were more likely to use performance enhancing drugs while those over 30 under the age of 30 had no intention of doping because they still felt strong and performing well (Chebet, 2014). Indeed, after 21 years, the more the age increases, the less we have high physical capacities and the more the performance decreases. In addition, the risk of doping is 25 times $(\mathrm{OR}=25.15 ; \mathrm{p}=0.0170)$ higher among respondents who clearly indicated their intention to dope compared to those who did not intend to dope. This risk is 5 times higher $(O R=5.10 ; p=0.0486)$ among respondents who had proposals for doping substances compared to those who had no proposals.

The results of the present study indicated a strong positive attitude towards doping, with $76.8 \%$ of athletes indicating that doping products are necessary to increase and improve their performance. Our results are close to those of Scarpino et al. (2010) who indicated a strong positive attitude towards doping, with $60 \%$ of athletes and coaches indicating that doping products are necessary to improve performance. These results contradict those of Chebet (2014) among Kenyan elite athletes, Alaranta et al. (2006) among elite athletes receiving financial support from the National Olympic Committee, Peretti-Watel (2005) among elite athletes, who found that more than $90 \%$ of athletes consider doping to be dishonest, unhealthy and hazardous and who believe that it is possible to achieve the highest level of performance without doping.

Regarding the practice of doping in sport, the present study indicates a very low use of doping products, substances and methods (9.4\%) among university athletes. However, it is possible that the current prevalence is much higher than that obtained, as most athletes may not wish to be directly associated with its use (Otieno, Ofulla, 2007). These authors indicate that young people feel comfortable answering a question about the possibilities of using drugs rather than a question about actual drug use. Our results are close to those of Scarpino (1990), where $10 \%$ of the study subjects admitted the use of different forms of doping substances and products. They are higher than those obtained by Muwongue and colleagues (2015) in Ugandan elite athletes, where $3.3 \%$ reported use of doping substances and methods among relatively weak athletes. Our results are also higher than those of Wroble and colleagues (2008) among elite athletes where a low rate ( $1 \%)$ of the prevalence of anabolic steroids was detected.

In this study, the majority of athletes have never been tested for doping (75.4\%). Knowing that there are only $63.6 \%$ of participants who take part in competitions, this observation could be also due to the lack of anti-doping tests in the country or when athletes fear being falsely identified as being doped or as actually doped and fear being caught (Muwongue et al., 2015). It is therefore 
important to note that athletes must be fully aware of and comply with any WADA anti-doping rule violations, as they also risk penalties.

\section{Conclusion}

Cameroonian university athletes have high knowledge about doping, potentially positive attitudes towards doping and low doping practice. Age, proposals for doping and intention to dope are predictors of doping in this population.

\section{References}

Al Ghobain et al., 2016 - Al Ghobain, M., Kombaz, M.S., Almassad, A., Alsultan, A., Al Shubaili, M., Al Shabanh, O. (2016). Prevalence, knowledge and attitude of prohibited substances use (doping) among Saudi sport players. Substance Abuse Treatment, Prevention and Policy, 11: 14. DOI: 10.1186/s13011-016-0058-1

Alaranta et al., 2006 - Alaranta, A., Alaranta, H., Holmila, J., Palmu, P., Pietila, K., Helenius, I. (2006). Self-reported attitudes of elite athletes towards doping: Differences between type of sport. International Journal of Sports Medicine. 27: 842-846.

Albrecht et al., 1992 - Albrecht, R.R., Anderson, W.A., McGrew, C.A., McKeag, D.B., Hough, D.O. (1992). NCAA Institutionally based drug testing: Do our athletes know the rules of this game? Medicine and Science in Sports and Exercise. 24: 242-246.

Ama et al., 2002 - Ama, P.F.M., Ama, V.J., Kamga, J.P., Sato, G., Laure, P. (2002). Dopage and sport: knowledges and attitudes of pharmacists in Yaounde. Science and Sports. 17(3). DOI: 10.1016/So765-1597(02)00132-6

Ama et al., 2003 - Ama, P., Betnga, B., Ama Moor, V.J., Kamga, J.P. (2003). Football and doping: Study of Africa amateur footballers. British Journal of Sports Medicine. 37: 307-310. DOI: 10.1136/bjsm.37.4.307

Bae et al., 2017 - Bae, M., Yoon, J., Kang, H., Kim, T. (2017). Influences of Perfectionism and Motivational Climate on Attitudes towards Doping among Korean National Athletes: A Cross Sectional Study. Substance Abuse Treatment, Prevention and Policy. 12(52): 1-8. DOI: 10.1186/s13011-017-0138-x

Blank et al., 2016 - Blank, C., Kopp, M., Niedermeier, M., Schnitzer, M., Schobersberger, W. (2016). Predictors of doping intentions, susceptibility, and behaviour of elite athletes: A metaanalytic review. SpringerPlus. 5(1): 1333. DOI: 10.1186/s40064-016-3000-o

Blank et al., 2016 - Blank, C., Schobersberger, W., Leichtfried, V., Duschek, S. (2016). Health Psychological Constructs as Predictors of Doping Susceptibility in Adolescent Athletes. Asian Journal of Sports Medicine. 7(4): e35024. DOI: 10.5812/asjsm.35024

Boit et al., 2015 - Boit, M., Dimeo, P., Onywera, V., Theuri, G., Kiplamai, F., Sigei, S., Stewart, D., Cronin, L. (2015). Doping Education status in Kenya. Evaluation of Knowledge, attitudes and practice of doping among elite Kenyan athletes. Report compiled for WADA. [Electronic resource]. URL: https://www.wada-ama.org/sites/default/files/resources/files/wadafinal-report-dr-dimeo.pdf (date of access: 18.04.2020).

Brand et al., 2014 - Brand, R., Wolff, W., Thieme, D. (2014). Using response-time latencies to measure athletes doping attitudes: The brief implicit attitude test identifies substance abuse in bodybuilders. Substance Abuse Treatment, Prevention and Policy. 10(9): 36. DOI: 10.1186/1747597X-9-36

Campian et al., 2018 - Campian, M.D., Flis, A.E., Teramoto, M., Cushman, D.M. (2018). Self-reported use and attitudes toward performance-enhancing drugs in ultramarathon running. Wilderness and Environmental Medicine. 29: 330-337. DOI: 10.1016/j.wem.2018.04.004

Chebet, 2014 - Chebet, $S$. (2014). Evaluation of knowledge, attitudes and practices on doping among elite middle and long distance runners in Kenya (Ph.D Thesis). Kenyatta University, Nairobi, Kenya.

Devcic et al., 2018 - Devcic, S., Bednarik, J., Maric, D., Versic, S., Sekulic, D., Kutlesa, Z., Bianco, A., Rodek, J., Liposek, S. (2018). Identification of Factors Associated with Potential Doping Behavior in Sports: A Cross-Sectional Analysis in High-Level Competitive Swimmers. International Journal of Environmental Research and Public Health. 15(8): 1720. 
Domagała-Rodacka et al., 2018 - Domagała-Rodacka, R., Rodacki, T., Owczarek, D., Cibor, D., Zagrodzki, P. Doping in sport - attitude and professional experience among physicians in Poland. Folia Medica Cracoviensia. LVIII(3): 35-47. DOI: 10.24425/fmc.2018.125071

Erdman et al., 2007 - Erdman, K.A., Fung, T.S., Doyle-Baker, P.K., Verhoef, M.J., Reimer, R.A. (2007). Dietary supplementation of high-performance Canadian athletes by age and gender. Clinical Journal of Sport Medicine. 17(6): 458-464. DOI: 10.1097/jsm.obo13e31815aed33

Government of Kenya, 2014 - Government of Kenya (2014). Anti-doping taskforce; Final report submitted to the Cabinet Secretary Ministry of Sports, Culture and the Arts on 7th April, 2014.

Hausmann et al., 1998 - Hausmann, R., Hammer, S., Betz, P. (1998). Performance enhancing drugs (doping agents) and sudden death - A case report and review of the literature. International Journal of Legal Medicine. 111: 261-264.

Honour, 2016 - Honour, J.W. (2016). Doping in sport: Consequences for health, clinicians and laboratories. Annals of Clinical Biochemistry. 53: 189-190.

Kondric et al., 2011 - Kondric, M., Sekulic, D., Petroczi, A., Ostojic, L., Rodek, J., Ostojic, Z. (2011). Is there a danger for myopia in anti-doping education? Comparative analysis of substance use and misuse in Olympic racket sports calls for a broader approach. Substance Abuse Treatment and Prevention Policy. 6: 27. DOI: 10.1186/1747-597X-6-27

Kreher, Schwartz, 2012 - Kreher, J.B., Schwartz, J.B. (2012). Overtraining syndrome: A practical guide. Sports health. 4(2): 128-138.

Ljungqvist, 2014 - Ljungqvist, A. (2014). The fight against doping is a fight for the protection of the clean athlete, the health of the athlete and the integrity of sport. British Journal of Sports Medicine. 48(10): 799. DOI: 10.1136/bjsports-2014-093654

Malek et al., 2014 - Malek, S., Taylor, J., Mansell, K. (2014). A questionnaire examining attitudes of collegiate athletes toward doping and pharmacists as information providers. Canadian Pharmacists Journal (Ott). 147(6): 352-8. DOI: https://doi.org/10.1177/1715163514552559

Mazanov et al., 2012 - Mazanov, J., Huybers, T., Connor, J. (2012). Prioritising health in anti-doping: What Australians think. Journal of Science and Medicine in Sport. 15: 381-385.

Moran et al., 2008 - Moran, A., Guerin, S., Kirby, K. (2008). The development and validation of a doping attitude and behaviour scale. Report submitted to the World Anti-doping Agency (WADA).

Morente-Sánchez et al., 2019 - Morente-Sánchez, J., Zandonai, T., Zabala Diaz, M. (2019). Attitudes, Beliefs and Knowledge Related to Doping in Different Categories of Football Players. Journal of Science and Medicine in Sport. 22(9): 981-986. DOI: 10.1016/j.jsams.2019.05.010

Morente-Sánchez, Zabala, 2013 - Morente-Sánchez, J., Zabala, M. (2013). Doping in sport: A review of elite athletes' attitudes, beliefs and knowledge. Sports Medicine 43(6): 395-411. DOI: https://doi.org/10.1007/s40279-013-0037-x

Muwongue et al., 2015 - Muwongue, H., Zavuga, R., Kabengue, P.A. (2015). Doping knowledge, attitudes, and practices of Ugandan athletes': a cross-sectional study. Substance Abuse Treatment and Prevention Policy. 10: 37. DOI: 10.1186/s13011-015-0033-2

Otieno, Ofulla, 2009 - Otieno, A.O., Ofulla, A.V.O. (2009). Drug Abuse in Kisumu Town in Western Kenya. African Journal of Food, Agriculture, Nutrition and Development. 9(3): 847-858

Perreti-Watel et al., 2005 - Perreti-Watel, P., Pruvot, S., Guagliardo, V., Gilbert, I., Obadia, Y. (2005). Attitudes toward doping among young athletes in Provence. Science and Sport. 20(1): 33-40.

Petroczi, Aidman, 2009 - Petroczi, A., Aidman, E. (2009). Measuring explicit attitude toward doping: Review of the psychometric properties of the performance enhancement attitude scale. Psychology of Sport and Exercise. 10: 390-396. DOI: https://doi.org/10.1016/j.psychsport .2008.11.001

Rintaugu, Mwangi, 2021 - Rintaugu, E.G., Mwangi, F.M. (2021). Knowledge, attitudes and perceptions on doping among university students in physical education and sport science related degree programmes. Journal of Human Sport and Exercise. 16(1): 174-186. DOI: https://doi.org/ 10.14198/jhse.2021.161.16

Scarpino et al., 1990 - Scarpino, V., Arrigo, A., Benzi, G., Garattini, S., La Vecchia, C., Bernadi, L.R., Silvestrni, G., Tuccimei, G. (1990). Evaluation of prevalence of doping among Italian athletes. Lancet. 336(8722): 1048-1050. 
Sekulic et al., 2016 - Sekulic, D., Tahiraj, E., Zvan, M., Zenic, N., Uljevic, O., Lesnik, B. (2016). Doping Attitudes and Covariates of Potential Doping Behaviour in High-Level Team-Sport Athletes; Gender Specific Analysis. Journal of Sports Science and Medicine. 15: 606-615.

Sommerville, Lewis, 2005 - Sommerville, S.J., Lewis, M. (2005). Accidental breaches of the doping regulations in Sport: is there a need to improve the education of the sports people? British Journal of Sports Medicine. 39: 512-516.

Waddington et al., 2005 - Waddington, I., Malcolm, D., Roderick, M., Naik, R. (2005). Drug use in English professional football. British Journal of Sports Medicine. 39: 4e18. DOI: 10.1136/bjsm.2004.012468

World anti-doping Agency.., 2011 - World Anti-Doping Agency Resource Guide. (2011). [Electronic resource]. URL: http://www.wadaama.org. (date of access: 16.04.2020).

World anti-doping Agency, 2009 - World anti-doping Agency. World Anti-Doping Code. In Doping Control: Definition of doping, 2009, Montreal, Quebec. (date of access: 16.04.2020).

World Anti-Doping Agency, 2015 - World Anti-Doping Agency. Anti-Doping Testing Figures, 2015. [Electronic resource]. URL: https://www.wada-ama.org/sites/default/files/resources/fils/ 2015_wada_anti-doping_testing_figures_report_o.pdf (date of access: 16.04.2020).

Wroble et al., 2008 - Wroble, R.R., Gray, M., Rodrigo, J.A. (2008). Anabolic steroids and preadolescent athletes: Prevalence, knowledge and attitudes. Sport Journal. 5(3). [Electronic resource]. URL: http://www.thesportjournal.org/article/anabolic-steroids-and-pre-adolescent-athletes-prevale nce-knowledge-and-attitudes 